\title{
A temporal perspective to empirically investigate the concept of social distance
}

\author{
Stefania Tusini ${ }^{1}$
}

Accepted: 8 January 2022 / Published online: 27 January 2022

(c) The Author(s), under exclusive licence to Springer Nature B.V. 2022

\begin{abstract}
The essay deals with the problem of the empirical analysis of the concept of social distance using a temporal rather than a spatial approach.

To this end, the Bogardus' Social Distance Scale is introduced by emphasizing that it was defined by employing a spatial perspective and describing the socio-cultural environment in which it was designed.

Then, it is illustrated a temporal perspective to empirically investigate the concept of social distance introducing the concepts of allochronism, social time and standard time. In particular, it is argued that social time has close connections with our perceptions, interpretations, values, needs and cultures, and as such is particularly suitable for investigating socio-temporal distance.

Moreover - as the main focus of this essay - the methodological procedure used by the author to examine the socio-temporal distance of ethnic relations between migrants and natives in Italy is illustrated. By comparing significant indicators suitable for assessing living conditions, it will become evident how the two social groups live in different temporal worlds, although they are physically contemporary. In particular, it is shown how migrants live in a temporal bubble that represents a "piece" of modernity inserted in a postmodern world.

It is concluded that studying social distance using a temporal approach is very effective and has several applications: it can be used not only for ethnic relations but also for research on minority, weak, marginal groups, in gender or intergenerational studies, and in all fields in which gaps/disparities/ inequalities must be compared.
\end{abstract}

Keywords Social distance $\cdot$ Temporal distance $\cdot$ Social time $\cdot$ Allochronism Migration · Ethnic relations

Stefania Tusini

stefania.tusini@unistrapg.it

1 Department of International Humanities and Social Sciences, University for Foreigners of Perugia, Perugia, Italy 
Social distance is a persistent theme in the history of the human sciences ${ }^{1}$ - especially in the field of sociological research — whose theorization was started by Simmel $(1903 ; 1908)$ in Europe, and by Park (1923) and Bogardus (1925a, 1926, 1928, 1933, 1967) in North America.

On this subject, Simmel formulated a sophisticated theory according to which the concept of social distance is both spatial (or physical) and metaphorical (or symbolic). Specifically, the former can be defined as physical segregation (residential, occupational, and so forth) and the latter as the degree to which individuals or groups share cultural and social similarities.

Nevertheless, in this essay it is Bogardus' proposal that sparks interest because of its operational implications. In fact, the famous Chicago scholar ${ }^{2}$ was the inventor of the Social Distance Scale that bears his name and which is — as well as the Likert scale (1932) — one of the best known and most widely used in the world.

Actually, the Social Distance Scale has been used globally to study ethnic relationships (Fedor 2021; Koc and Anderson 2018; Weaver 2008; Sakuragi 2006; Parillo and Donoghue 2005; Randall and Delbridge 2005; McAllister and Moore 1991; Zaidi 1967) but also (to mention the main ones) attitudes toward sexual behaviour, gender and homosexuality (Benitez et al. 2017; Górska et al. 2017; Dufwenberg and Muren 2006; Hinrichs and Rosenberg 2002; Gentry 1987; Staats 1978), religious differences (Brockett et al. 2009; Brinkerhoff and Mackie 1986; Cavan 1971; Nataraj 1965; Hunt 1956), deviance and social conflict (Arteaga and Lara 2004; Haney and Fein 1968), educational fields (Kovačević and Radovanovic 2020; Maurer and Keim 2018), racism and discriminations (Yang 2015; Morgan 2006; Cover 1995; Sell 1990; Kinloch 1973; Morsbach and Morsbach 1967), physical and mental disabilities (Fujii et al. 2018; Adewuya and Makanjuola 2005; Stevenson 1991; Eisenman 1986; Bagley 1972; Benton et al. 1968), social classes and poverty (Sacks and Lindholm 2002; Nix and BlairLoy 2000; Dickson and MacLachlan 1990), tourism (Thyne et al. 2022; Çelik 2019; Woosnam and Lee 2011), professional positions (Leong and Tang 2016; Prandy and Jones 2001; Bourgeois and Friedkin 2001; Prandy 1990; Laumann and Senter 1976; Laumann and Guttman 1966; Singh 1965), innovation (Rostova and Urgalkin 2019), human-robot relationships (Banks and Edwards 2019; Kim and Mutlu 2014), and the like.

In addition, the scale has often been modified to accommodate different spatiotemporal contingencies and research fields (Coventry and Case 2020; Mather, Jones and Moats 2017; Parrillo and Donoghue 2005; Lee, Sapp and Ray 1996; Byrnes and Kiger 1988; Smith 1970; Ames and Arline 1969 - to mention a few).

As known, at the time when Bogardus was a doctoral student and a young professor, the United States experienced the so-called "second wave" of immigration during which, unlike the first, many non-Protestant people came to North America from Europe, Asia (especially from Japan) and Central America. Some cities saw an impetuous growth in population. For example, Chicago - where Bogardus was a student—-between 1880 and 1890 doubled its population (to 1 million), and over the next 20 years doubled it again (to 2 millions).

\footnotetext{
${ }^{1}$ The concept of social distance (with which this essay is concerned) should not be confused with the concept of social distancing which, as well known, is a practice for containing Covid-19 contagion.

${ }^{2} \mathrm{He}$ received a Ph.D. from the University of Chicago in 1911 and then joined the University of Southern California as a Professor of Sociology.
} 
Immigrants brought with them different languages, customs, religions, causing concerns, fear and prejudices. Consequently, in order to control foreign-born individuals and contain new arrivals, many racial laws have been enacted by both the federal government and several states ${ }^{3}$.

In those days, there were also significant internal migratory flows of black people moving from southern to northern states in search of better working conditions and greater civil rights. The segregation in which they lived (even in the northern states) led them to protest. Especially during the summer of 1919 many riots broke out all over the United States. One of the most frightening took place in Chicago where almost 40 people were killed, more than 500 were injured and more than 1,000 houses were destroyed. This caused the re-emergence of racial groups such as the KKK which, just to mention one event, attracted as many as 25,000 members and sympathizers at a rally held in Chicago in 1922 (Spinney 2000).

This incendiary situation contributed to increased interest in racial and immigration issues among scholars (McKee 1993). Thomas, Znaniecki, Park and Burgess were among the first to take up this topic, and the Chicago School inaugurated a branch of research that became one of its flagships. Bogardus was exposed to this socio-political and intellectual climate and began to develop an interest in immigration and race attitudes (1928).

Robert Park (inspired by Simmel ${ }^{4}$ ) defined social distance as "an attempt to reduce to something like measurable terms the grades and degrees of understanding and intimacy which characterize personal and social relations generally" (Park 1923, p. 39), and prejudice as "the more or less instinctive and spontaneous disposition to maintain social distances" from other groups or people (Park 1923, p. 343).

This concept was employed in his famous 1924 Pacific Coast Race Relations Survey in which Bogardus worked as regional director (Bogardus 1959). On that occasion he was urged by Park to design a "quantitative indicator of social distance" (Harvey 1987, p. 80) and thus designed the Social Distance Scale: a pioneering and enduring tool in the field of empirical research on race and ethnic relations (Faris 1967, p. 108); a simple (perhaps simplistic) but functional empirical tool.

In his 1925 paper Measuring Social Distances (1925a) Bogardus presented the first version of the Scale. In practice, as well known, respondents were asked to say the closest relationship they were willing to accept with a member of each of the ethnic/racial groups indicated (Mexican, Chinese, Italian, German, ...) thinking of each group as a whole: "to close kinship by marriage, to my club as personal chums, to my street as neighbours, to employment in my occupation, to citizenship in my country, as visitors only to my country, would exclude from my country" (Bogardus 1925a, Document I).

One year later, in 1926, "with the help of faculty members from 25 universities and colleges, Bogardus administered the Social Distance Scale Survey with race as the focus of interest, and he subsequently used it every 10 years through 1966, with the exception of

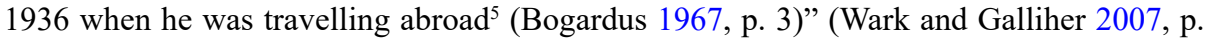
391).

\footnotetext{
${ }^{3}$ It should be noted that the state of California, where Bogardus had his first professorship, was indeed brutal toward the second wave of migration, especially of Japanese origin (Roesch 2015).

${ }^{4}$ It is well known that Park was a student under Simmel.

${ }^{5}$ Beginning in 1977, after Bogardus' death, the survey was administered again by Carolyn Owen, Howard Eisner and Thomas McFaul (1977).
} 
In 1933 Bogardus proposed some slight modifications to the scale: would marry, would have as regular friends, would work beside in an office, would have several families in my neighbourhood, would have merely as speaking acquaintances, would have live outside my neighbourhood, would have live outside my country. Unlike in the past, this time he borrowed Thurstone's idea of using 100 judges to select items (Thurstone and Chave 1929).

The Scale represents the operational definition of the concept of social distance as defined by its author: "the degrees and grades of understanding and feeling that persons experience regarding each other. It explains the nature of a great deal of their interaction. It charts the character of social relations. The measurement of social distances is to be viewed simply as a means for securing adequate interpretations of the varying degrees and grades of understanding and feeling that exist in social situations" (Bogardus 1925a, p. 216). In particular, social distance is "the degree of sympathetic understanding that exists between two persons or between a person and a group" (1933, p. 270).

In doing so, Bogardus combined geo-spatial and psycho-social factors; namely, he intended to evaluate Ego's willingness to accept Alter as a result of the physical distance that Ego himself claimed to want to maintain. In other words, he postulated a close connection between spatial distance and symbolic distance but, according to some critics (Ethington 1997), underestimating the multidimensionality of the concept and avoiding problematizing the link between the two ${ }^{6}$.

It is true that Bogardus did not spend so much time analysing the concept of social distance because he thought that its meaning was very simple and obvious. Instead, he tried to analyse some dimensions related to the concept such as the origin of social distance, the difference between vertical and horizontal distance, the relationship with the status of individuals and the like (1925b).

Although his work inevitably reflects a Geistzeit and a certain methodological "looseness" that has characterized the Chicago School on several occasions, in my opinion Bogardus has at least one great merit: to have constructed an empirical (and not only theoretical) tool to investigate the concept of social distance, and to have made it available to the scientific community ${ }^{7}$. As mentioned in the introduction, generations of scholars have grappled with this tool: using it in their investigations, criticizing or modifying it to suit it to their scientific needs. This seems sufficient to demonstrate its heuristic richness.

At the same time, I agree that employing only a physical point of view to address social distance is too reductive for the social sciences because it is evident that cultural distance also plays an important role in the dynamics of ethnic interaction and integration. For instance, if we think about the mere physical distance that separates Africa from Europe, it is clear that they are spatially closer than Europe and South America. But, for a number of reasons that cannot be discussed here, thinking in terms of cultural distance leads us to the

\footnotetext{
6"The concept of «social distance» began in the mind of Georg Simmel as a complex interpretation of sociality as forms of «distance» in both a geometric (i.e. Euclidian) and a metaphoric sense. In the hands of Simmel?s American student Robert Park and his «Chicago School» of Sociology—most notably the work of Emory Bogardus - however, the concept was impoverished by stripping away Simmel's geometric sense of distance" (Ethington 1997).

${ }^{7}$ In general, I very much appreciate the hard work required to build what Elster calls "nuts and bolts" (1989; 2007), namely the basic disciplinary tools. Undoubtedly, operational definitions of sociological concepts are part of them because, in my opinion, Sociology is just that: an empirical science that as such needs theory as much as empirical tools for data collection.
} 
opposite conclusion: in fact, in a hypothetical geo-temporal map, South America would be closer to Europe than Africa due to of their greater cultural proximity.

Following this line of thought, my intention here is to present an empirical way of investigating the concept of social distance from a temporal point of view able to broaden the perspective. It is a fact that the concept of social distance (even in the modified versions of the scale) has nearly always been presented in terms of spatial distance. On the contrary, my attempt is precisely to employ a temporal dimension to assess social distance and study ethnic relations.

This is not a proposal to replace one approach with the other, but to integrate the two wherever possible. Bogardus attempted to quantify the social distance by scoring each item, calculating three different indices - SCR (social contact range); SCD (social contact distance); SCQ (social contact quality) - and consequently constructing a social distance ranking of the ethnic groups proposed to the respondents (1925a). With the same intention, I will try to use indicators and data to evaluate (quantify) the socio-temporal distance between different ethnic groups in order to reconstruct an overview of their relationships.

Moreover, before entering in media res, it seems useful to note that spatial distance is a synchronic concept, while temporal distance is diachronic. Consequently, the latter allows us to imagine sociological landscapes that are impossible to see if we only look at the "world in the present". In other words, I will try to show how the "here and now" could be integrated with other dimensions that are very rich in information about social distance, difference, diversity, otherness (Tusini 2014; 2020).

\section{Standard time, social time. When phenomenology is not enough}

It is necessary to begin by saying something about the concept of time ${ }^{8}$ and in particular about the analytical distinction between social (or qualitative) time and standard (quantitative or historical) time which is well known in the sociological field.

Standard time is marked by clocks and calendars. Despite being artificially created, it has long since become the indispensable "rhythm" (Zerubavel 1981) by which almost all social activities move (Simmel 1903). Its pervasiveness is such that we all believe that our (Western) way of thinking and counting time is natural, necessary and universal. This is not so, for at least two reasons.

First: numerous anthropological studies have long shown that our way of thinking and counting time is only one of the existing types. To mention just a few examples: the Balinese studied by Geertz (1973) used no less than two crossed calendars to measure the passing of time, and Muslim countries count years and months starting from the Hegira (i.e. Muhammad's escape from Mecca) and not from Jesus' birth. The former calendar, in fact, marks the year 1442 while the latter 2021.

Second: as is well known, there are very different perspectives and perceptions of time even within the same socio-cultural system. They are often linked to socio-demographic factors such as age, professional position, cultural level, health status, living conditions and the like. So, such perspectives and perceptions of time are social constructions (just to cite

\footnotetext{
${ }^{8}$ This very complex and important topic would certainly deserve greater consideration. Nonetheless, it will be covered briefly here. This might raise some criticism, but this article has its own focus and there is no room for a broader discussion.
} 
the pioneers of this research fields: Jahoda, Lazarsfeld and Zeisel 1933; Sorokin and Merton 1937; Coser and Coser 1963).

In spite of the fact that our current mental habits lead us to believe otherwise, alongside standard time there is another time which was predominant in the "monde de l'«à-peuprès»" (Koyré 1961), older and more linked to natural cycles than the standard one and that cannot be ignored even in our age characterised by an ever-increasing need for precision: the social time. It may seem strange, but until recently each village had its own way of measuring time and punctuality was neither appreciated nor necessary as it is today ${ }^{9}$ (Zerubavel 1981; 1982).

Social time has a qualitative nature: it is a lived time used by society and individuals to express meanings, values and needs. It is useful for defining attitudes, expectations and life paths. Consequently, it could hardly be described by clocks or calendars (Adam 1995; 2004) because of his connection with our perceptions, interpretations and cultures.

It does not move uniformly as standard time does. It flows at its own pace: it slows down, speeds up, stops, regardless of the constant motion of the clock. Each of us can testify the relativity of individual perceptions of duration: an hour seems very long if we are bored, and it flies if we are having fun. Consequently, this implies that different social and individual representations of time coexist together.

For the purposes of this essay, it means that the socio-temporal condition of a group (or an individual) is a social construction (Elias 1984) composed of many "ingredients" that make up different life trajectories. These factors construct unequal life paths and define heterogeneous social groups experiencing (social) worlds that differ in conditions, constraints and possibilities.

A reflection on the use of time as a tool for social research was started a few years ago by some scholars belonging to interpretative and critical anthropology (Geertz 1973; Clifford and Marcus 1986, to cite the most famous). Some of them denounced how traditional ethnography used its scientific tools to place otherness on an evolutionary ladder of civilization in order to support Western colonial enterprise.

At this end, spatial distance and temporal distance were systematically overlapped. Namely, people who lived physically elsewhere (in another region of the Earth) were also considered to be living in a temporal elsewhere, even though they shared the same historical period with the observer.

In particular, Fabian (1983) has thoroughly studied the use of temporal distance as a control tool and the main concepts that revolve around it such as civilization, evolution, development, acculturation, modernization, industrialization, urbanization, primitive, savage, tribal, traditional, Third World, which might seem neutral but are temporally (and politically) connoted.

According to his studies "the effect of such strategies [is] a «denial of coevalness» and the resulting discourse [is] «allochronic»" (Fabian 1983, p. 173). Allochronism is an attitude

\footnotetext{
${ }^{9}$ For instance, "by mid-19th century practically hundreds of standards of time were in use throughout the [United States]. To take just the Midwest, for example, there were 38 standards of time in Wisconsin, 27 in Michigan, 27 in Illinois, and 23 in Indiana". Consequently, the railway situation was quite chaotic and involved serious practical difficulties in using it effectively: "At the train station in Buffalo, for example, there were three different clocks indicating three different times. While one of these showed Buffalo time, the second was set on New York time and was relevant only to passengers using the New York Central trains, whereas the third was set on Columbus time and was relevant only to passengers using the Lake Shore and Michigan Southern trains" (Zerubavel 1982, p. 9).
} 
of distancing through time rather than space. As already mentioned, it is the refusal to consider members of other cultures as fully belonging to the observer's present, placing them in another, backward and primitive temporality. As matter of fact, this research practice replaced contemporary with allochronism.

Fabian suggested overcoming allochronism and epistemic injustice (Fricker 2009) by adopting the concept of universal coevalness and claiming that all humans live coevally. This is a very universalistic and politically correct solution, and at first glance it is tempting to adhere to it completely. Unfortunately, on further thought, it sounds too ideological for science. In fact, in my opinion, the concept of universal coevalness, advocated by Fabian, risks hiding real and significant gaps characterizing different social groups (Bevernage 2016).

Let me explain my point of view by comparing, for example, Italians and Ivorians. It should not be difficult to realize that they have very different living conditions because of their spaces of experiences and horizons of expectations ${ }^{10}$ (Koselleck 1979). They have (very) unlike material needs, health status, beliefs, priorities, life expectancy, attitudes, possibilities, consumptions, and so on. This is a fact, a crude truth; not an intellectual construct.

Following Fabian, we could claim the contemporaneity of the two populations. In terms of standard time it is correct: all in all, they are living simultaneously. But, analysing them in terms of social time, their social distance becomes evident. Can we affirm that their living conditions represent the same social framework? Certainly not. In order to account for these differences, we have to accept the fact that although the two populations are historically contemporary, they actually live in different socio-temporal worlds.

It should be added that comparing people from such different cultures and living in countries with such marked socio-economic differences is quite easy (so to speak). It is more difficult to bring to light the underlying socio-temporal cleavages by investigating apparently similar social groups living within the same country/culture. Therefore, it is necessary to determine how to operationally define the concept of socio-temporal distance in order to use it in domestic empirical research.

\section{Operationally defining the concept of social distance by a temporal perspective}

To show how to empirically use the concept of socio-temporal distance, I will illustrate a research I conducted in Italy comparing Italians and migrants.

At the end of this section I am going to conclude that in Italy migrants live in a temporal apartheid condition because they are allochronic with respect to the natives; that is, the two social groups do not "exist" in the same social time. But the conclusion is not that relevant

\footnotetext{
${ }^{10}$ Koselleck (1979) claimed that the intertwining between Erfahrungsraum (experience, i.e. the past) and Erwartungshorizont (expectation, i.e. the future) is historically variable and shapes different types of historical time. According to him, different weights were given to the past, present, and future in different periods, thus constructing distinct "temporal landscapes": in the European Middle Ages the past dominated the present and the future; the future was emphasized in the period of the Enlightenment (characterized by the idea of a necessary and ineluctable progress); now we are living in the "eternal present" era, pointed out by several scholars as the prevailing existential condition in the contemporary world (Beck 1992). This is true for sociocultural systems, but also for individuals who have past experiences behind them and cultivate expectations and hopes for the future. Individuals belong to specific social groups according to their temporal position and, through the intersection of these coordinates, generate polysemic conceptions of time.
} 
here. Far more significant is understanding the way by which that conclusion was reached. I'm going to illustrate it below, starting with the main concepts.

The concept of allochronism conceived by Fabian is not only temporal but also relational, and therefore does not make sense without comparison. Consequently, to assess the temporal distance between (at least two) different social categories (in my case: migrants and natives) it was necessary to find adequate empirical indicators.

At the beginning, aware of the limitations of such a choice but supported by Feuerbach's aphorism "Man is what he eats" (1862), I selected a set of socioeconomic indicators ${ }^{11}$ (such as average age, household composition, housing status, possession of durable goods, fertility rate, employment status, and so on) that could define the living conditions of both social groups.

Choosing relevant indicators is very important, of course. In fact, each of them must have a strong theoretical basis and not represent just a simple number. For instance, average age is not just an important demographic figure, but it can say something on the structure of families and society, on the perceptions of the future, on the welfare system's sustainability, on the families' survival strategy, and the like ${ }^{12}$.

Therefore, founding a constellation of significant and theoretically supported indicators means being able to trace a socio-temporal portrait of the social groups under investigation and mark temporal boundaries between them.

Once the indicators were chosen, I looked for data on natives and migrants to compare their living conditions "here and now". This comparison was useful but represented only a synchronic analysis like thousands of others already existing in the international literature (especially in research on social integration). It was clear that this way did not allow to reach the set goal because was not yet adequate to investigate the temporal "position" of migrants.

In fact, in order to carry out a diachronic analysis, it was necessary to take data on migrants back in time (so to speak) to the point where they matched those of natives. This seemed to me a suitable way to estimate the temporal "position" of migrants in relation to natives. Let me explain further how I developed this approach.

Reading a report on family size in Italy, I noticed a high incidence (about 30\%) of extended families among migrants: it was too high compared to natives and unusual for our contemporary urbanized lifestyle.

Extended families were very widespread in pre-industrial Italy (almost $45 \%$ in the first decades of the last century). In those days, it was a family organization really functional for survival and capable to guarantee better living conditions and protection from a social and economic point of views (probably the same reasons that today push migrants to cohabitation). Due to modernization (which began in the late $1950 \mathrm{~s}$ ), the incidence of this type of family is gradually decreasing to almost 5\% in 2019 (Istat 2011a).

This statistic, although interesting, was not satisfactory to reach the aim because-as said - it was collected using a synchronic dimension. In order to make a diachronic comparison, it was necessary to consult data capable of answering the following question: how long ago were about $30 \%$ of Italian families extended?

The general idea — as said above - was based on the conviction that, in order to evaluate the socio-temporal distance between natives and migrants, it might be useful to diachronic-

\footnotetext{
${ }^{11}$ All in all, this choice should not be so wrong if material living conditions are one of the main theoretical pillars generally used to analyse the social integration level (another is the cultural one, of course).

${ }^{12}$ By the way, today migrants in Italy are on average 35 years old, while Italians are almost 46.
} 
ally compare some significant indicators able to characterize their living conditions. In this sense, confronting the numerical composition of native and migrant households was only the first step for studying their allochronic relations.

This early analysis showed that the two social groups, while undoubtedly sharing the same historical present (they were contemporaries), lived in different social times. On the basis of census data, we saw that Italians had about 30\% of extended families around 1950. Consequently, it was possible, in relation to this indicator, to estimate a socio-temporal distance between the two social groups of about 70 years. And, with reference to the average age mentioned above, Italians were about 35 years old (i.e., the average age of today's migrants) between the 1950 and $1960 \mathrm{~s}$, marking a socio-temporal distance of about 50 years between the two social groups.

Some other interesting dimensions have been employed, of course. The possession of durable goods is considered among the main ones. This is a very significant dimension because, as we know, the possession of a certain type of goods marked the transition from a traditional lifestyle to the modern consumer society. Put simply, it marks the passage from subsistence to prosperity, and for this reason is particularly meaningful in characterizing socio-temporal positions.

As is well known, the American sociologist David Riesman during the 1960 s called "standard package" the necessary package of economic goods families perceived as necessary for the American style of life. According to Riesman (1964), objects included in the standard package are loaded with symbolic meaning and their possession carries membership in the American middle class. Similarly, a few years later, the Italian sociologist Alberoni (1968) called them "beni di cittadinanza" (citizenship goods: TV, washing machine, refrigerator, and the like), arguing that their possession meant entry into the consumer society for millions of Italians who were leaving rural areas to move to urban and industrialized ones.

Looking at the data, we see that today only $78 \%$ of immigrant families in Italy own their own washing machine; Italians reached this rate in 1975. A refrigerator and a television set are owned by $86 \%$ of immigrant families, the same as Italian families around 1972. Lastly, nowadays only $52.4 \%$ of migrants own a car, while Italians reached this rate in 1971 (Istat, Serie storiche). Thus, the socio-temporal distance between natives and migrants in this case is about 50 years.

Moreover, to date $63.5 \%$ of foreign families have only one breadwinner, against $45.5 \%$ of Italian families. By consulting the Bank of Italy data it was possible to go back only to 1968 when $56 \%$ of Italian families had only one breadwinner. Given that this percentage has decreased over time ( $49 \%$ in 1972 and $39.5 \%$ in 1978), it is possible to assume that to find a share of Italian families having only one breadwinner equal to that of today's foreign families it is necessary to step back further in time, perhaps beyond the $1950 \mathrm{~s}$ (Banca d'Italia 1968).

Since the aim is not to illustrate the research results per se but rather its methodological potential, from here on only a few other descriptive elements will be added without dwelling on statistical details.

In order to reconstruct the overall picture, some other dimensions were analysed. Among others: (a) the progressive ethnicization of some types of jobs, the so-called "3D jobs": dirty, dangerous and degrading (Walzer 1983). In fact, migrants are permanently included in the lower segments of the labour market and do jobs that Italians no longer want to do, but that they did in the past; (b) the duration of working life, which is longer for migrants than for 
natives: on average they start earlier and end later, just like the Italians did a few generations ago; (c) the poverty conditions: very often migrants' families experience severe deprivation and represent a typical case of working poor ${ }^{13}$, in which work income is insufficient to support the family because of the high number of members; this is just like most Italians before modernization (Cingano et al. 2013; Banca d'Italia); (d) finally, the housing conditions: on average, migrant families experience overcrowding and housing poverty. They generally live in older and dilapidated buildings than the natives, and have fewer rooms and fewer square meters per capita than Italians. It may seem strange, but these housing conditions are very similar to what we Italians had on average not many decades ago (Istat 2019; 2021).

Synthetically concluding, migrants in Italy seem to live according to socio-economic parameters typical of a very different period from the contemporary one. This diachronic analysis shows how the living conditions of today's migrants in Italy seem more or less the same as those of Italians during the transition to modernization, between the late fifties and the mid-seventies (depending on the indicators).

Applying Fabian's terminology, we can state that migrants live in an allochronic state compared to natives, even though they both live in the same historical period, in the same city, often in a nearby apartment. Using a sentence cognitively disorienting, we could say that "they are here, but not now". They are here physically, but not socio-temporally.

It is not so easy to imagine people physically coexisting but living at different times. In fact, common sense leads us to consider it obvious that two social groups sharing the same space are also living in the same time. Unfortunately, it can happen that the use of common sense is very limiting to scientific thinking.

In this sense, the methodological reflection carried out by Lazarsfeld (1949) analysing the results of The American Soldier provides an instructive example. He examined a list of ex ante assumptions made on the basis of common sense (and apparently very reasonable) such as:

1. "Better educated men showed more psycho-neurotic symptoms than those with less education. (The mental instability of the intellectual as compared to the more impassive psychology of the-man-in-the-street has often been commented on).

2. Men from rural backgrounds were usually in better spirits during their Army life than soldiers from city backgrounds. (After all, they are more accustomed to hardships).

3. Southern soldiers were better able to stand the climate in the hot South Sea Islands than Northern soldiers (of course, Southerners are more accustomed to hot weather).

4. White privates were more eager to become non-coms than Negroes. (The lack of ambition among Negroes is almost proverbial).

5. Southern Negroes preferred Southern to Northern white officers. (Isn't it well known that Southern whites have a more fatherly attitude toward their «darkies»?).

6. As long as the fighting continued, men were more eager to be returned to the States than they were after the German surrender. (You cannot blame people for not wanting to be killed)" (Lazarsfeld 1949, p. 380).

Lazarsfeld demonstrated that these hypotheses were completely unfounded if compared with conclusions drawn on the basis of scientific evidence: "Every one of these statements is the direct opposite of what actually was found. Poorly educated soldiers were more neurotic

${ }^{13}$ Today, $49.1 \%$ of foreign families are at risk of poverty, compared to $17.4 \%$ of Italian-only families (Istat 2011b). 
than those with high education; Southerners showed no greater ability than Northerners to adjust to a tropical climate; Negroes were more eager for promotion than whites; and so on" (Lazarsfeld 1949, p. 380).

Going beyond common sense means opening up to the possibility of "seeing" scenarios that are not merely phenomenological or taken for granted.

It is the same when I affirm that migrants in Italy live in a kind of temporal apartheid. The empirical data taken together describe migrants as being stuck at a point back in time, as if they lived in a world apart according to the parameters of another era. Put it differently, it is as if they lived in a sort of time bubble representing a "piece" of modernity inserted in a postmodern society.

\section{Conclusion}

In this essay it was shown that the concept of social distance can be operationally defined as physical distance (à la Bogardus) but also as temporal distance. To do so, we compared natives and migrants living conditions by operationally defined their temporal distance using statistical data collected for other research purposes (no individual perceptions or feelings directly requested from respondents were used - nothing wrong with the latter, but we preferred otherwise).

Clearly, we are aware that comparing data so distant in time (in this research, up to 70 years sometimes) certainly poses more of a problem. Furthermore - and this is really crucial - it is necessary to point out that this proposal has absolutely no evolutionary or deterministic intention. Indeed, taking this approach in no way implies thinking that migrants will move along the "same line" as natives or similar.

This analysis is instead useful for capturing comparative "freeze frames" and using them to construct theoretical hypotheses suitable for interpreting the complexity of an increasingly stratified contemporary world. In fact, exactly quantify the distance of each singular indicator is not so important. Much more significant is the overall picture and the consequent theoretical implications drawing from it.

Just to give a few examples: the fact that migrants in Italy have such backward living conditions compared to natives can be read in the perspective of a natural adaptation process and a progressive improvement starting with the first generation migrants (still in great majority in Italy). In this case the leading idea is that, due to the succession of generations, the socio-temporal gap will be reduced.

Or, alternatively, you can read it through Merton's strain theory (1949) concluding that a dangerous gap is being built between the goals proposed to migrants as socially desirable and the means at their disposal to achieve them. In fact, the goals are formulated in the present and (maybe) achievable in the future, while the means (as we have seen above) are in the past and as such are inadequate or insufficient to achieve the set goals. In this case, the temporal mismatch can easily produce, citing Merton's typology, potentially non-conformist and even rebellious outcomes, especially in the second/third generations (looking at some indicators related to the Italian second generations, this seems to be the more likely scenario).

In conclusion, it should be added that-like the Bogardus Scale- the applications of the temporal approach are multiple: it can be used not only to study ethnic relations but 
also (to give a few examples) in researches on the social conditions of different minority, weak, marginal groups, in gender studies, in intergenerational studies and in all those fields where gaps/disparities/inequalities have to be compared. It is my conviction that using the temporal dimension along with the physical one will allow to enrich our knowledge about social distance.

Funding: This study was supported by University for Foreigners of Perugia Research Founds

Availability of data and material: not applicable

Code availability: not applicable

\section{Declarations}

Conflicts of interest/Competing interests: none

\section{Bibliography}

Adam, B.: Time. Polity Press, Cambridge (2004)

Adam, B.: Timewatch. The social analysis of time. Polity Press, Cambridge (1995)

Adewuya, A., Makanjuola, R.O.A.: Social distance towards people with mental illness amongst Nigerian university students. Social Psychiatry and Psychiatric Epidemiology. 40, 865-868 (2005). doi:https:// doi.org/10.1007/s00127-005-0965-3

Alberoni, F.: Statu nascenti. il Mulino, Bologna (1968)

Ames, R., Arline, F.S.: Criteria for evaluating others: A re-examination of the Bogardus social distance scale. Sociology and Social Research 54(1), 5-24 (1969)

Arteaga, N., Lara, V.L.: Violencia y distancia social: una revisión. Papeles De Poblacion. 10(40), 169-191 (2004). http://www.scielo.org.mx/pdf/pp/v10n40/v10n40a10.pdf

Bagley, C.: Social prejudice and the adjustment of people with epilepsy. Epilepsia. 13( 1), 33-45 (1972). doi: https://doi.org/10.1111/j.1528-1157.1972.tb04547.x

Banca d'Italia: Bilanci delle famiglie italiane (1968). https://www.bancaditalia.it/statistiche/tematiche/indagini-famiglieimprese/bilanci-famiglie/index.html

Banca d'Italia: Statistiche. https://www.bancaditalia.it/statistiche/

Banks, J., Edwards, A.: A common social distance scale for robots and humans. 28th IEEE International Conference on Robot and Human Interactive Communication (RO-MAN), pp. 1-6 (2019). doi: https:// doi.org/10.1109/RO-MAN46459.2019.8956316

Beck, U.: Risk society: Towards a new modernity. Sage, London (1992)

Benitez, D., Pereira, L., Orta, Y.: Social representation of homosexuality in young Cuban universities. Revista Chakiñan de Ciencias Sociales y Humanidades. 3, 41-58 (2017). http://scielo.senescyt.gob.ec/ scielo.php?script=sci arttext\&pid=S2550-67222017000200041\&lng=es\&nrm=iso\&tlng=es

Benton, R.G., Siegel, R., Derrick, J., Wallace, J.: Social-distance preferences among female and male medical students and cardiac patients toward various diseases and disabilities. Perceptual and Motor Skills. 27, 512-514 (1968). doi:https://doi.org/10.2466/pms.1968.27.2.512

Bevernage, B.: Tales of pastness and contemporaneity: on the politics of time in history and anthropology. Rethinking History (2016). https://doi.org/10.1080/13642529.2016.1192257

Bogardus, E.S.: Measuring social distances. Journal of Applied Sociology. 9, 299-308 (1925a). https:// brocku.ca/MeadProject/Bogardus/Bogardus_1925c.html

Bogardus, E.S.: Social distance and its origins. Journal of Applied Sociology. 9, 216-226 (1925b)

Bogardus, E.S.: Social distance in the city. Proceedings and publications of the American Sociological Society. 20, 40-46 (1926)

Bogardus, E.S.: Immigration and race attitudes. Heath and Company, New York (1928)

Bogardus, E.S.: A social distance scale. Sociology and Social Research. 17, 265-271 (1933)

Bogardus, E.S.: Social distance. Antioch Press, Yellow Springs, Ohio (1959)

Bogardus, E.S.: A forty-year racial distance study. University of Southern California Press, Los Angeles (1967) 
Bourgeois, M., Friedkin, N.E.: The distance core: Social solidarity, social distance and interpersonal ties in core-periphery structures. Social Networks. 23(4), 245-260 (2001). doi:https://doi.org/10.1016/ S0378-8733(01)00033-8

Brinkerhoff, M.B., Mackie, M.M.: The applicability of social distance for religious research: An exploration. Review of Religious Research. 28(2), 151-167 (1986). doi:https://doi.org/10.2307/3511469

Brockett, A., Village, A., Francis, L.J.: Internal consistency reliability and construct validity of the attitude toward Muslim proximity (AMPI): A measure of social distance. British Journal of Religious Education. 31(3), 241-249 (2009). doi:https://doi.org/10.1080/01416200903112417

Byrnes, D.A., Kiger, G.: Contemporary measures of attitude toward Blacks. Educ. Psychol. Measur. 48(1), 107-118 (1988). doi:https://doi.org/10.1177/001316448804800113

Cavan, R.S.: A dating-marriage scale of religious social distance. Journal for the Scientific Study of Religion. 10(2), 93-100 (1971). doi:https://doi.org/10.2307/1385297

Çelik, S.: Does tourism reduce social distance? A study on domestic tourists in Turkey. Anatolia. 30(1), 115-126 (2019). doi:https://doi.org/10.1080/13032917.2018.1517267

Cingano, F., Giorgi, F., Rosolia, A.: Lavoro, retribuzioni e vulnerabilità. In: Saraceno, C., Sartor, N., Sciortino, G. (a cura di): Stranieri e disuguali. Le disuguaglianze nei diritti e nelle condizioni di vita degli immigrati, 87-109. il Mulino, Bologna (2013)

Clifford, J., Marcus, G.E. (eds.): Writing culture. The poetics and politics of ethnography. University of California Press, Berkeley-Los Angeles (1986)

Coser, L.A., Coser, R.L.: Time perspective and social structure. In: Gouldner, A.W., Gouldner, H.P. (eds.) Modern sociology, 638-650. Harcourt, Brace and World Inc., New York (1963)

Coventry, B.T., Case, P.: Fifty shades of social distance. Women's Studies. 49(1), 83-100 (2020). doi:https:// doi.org/10.1080/00497878.2019.1695612

Cover, J.D.: The effects of social contact on prejudice. The Journal of Social Psychology. 135(3), $403-405$ (1995). doi:https://doi.org/10.1080/00224545.1995.9713968

Dickson, J.P., MacLachlan, D.L.: Social distance and shopping behavior. JAMS. 18(153)-161 (1990). doi:https://doi.org/10.1007/BF027264311990

Dufwenberg, M., Muren, A.: Generosity, anonymity, gender. Journal of Economic Behavior \& Organization. 61(1), 42-49 (2006). doi:https://doi.org/10.1016/j.jebo.2004.11.007

Eisenman, R.: Social distance ratings toward blacks and the physically disabled. College Student Journal. 20, 189-190 (1986). doi:https://doi.org/10.1177/0034355217727600

Elias, N.: Über die Zeit. Arbeiten zur Wissenssoziologie II. Suhrkamp, Frankfurt am Main (1984)

Elster, J.: Nuts and bolts for the social sciences. Cambridge University Press, Cambridge (1989)

Elster, J.: Explaining social behaviour. More nuts and bolts for the social sciences. Cambridge University Press, Cambridge (2007)

Engel, E.: Die Lebenskosten belgischer Arbeiterfamilien früher und jetzt. Bulletin de l'Institut International de Statistique. 9, 1-124 (1895)

Ethington, P.J.: The intellectual construction of "social distance". Toward a recovery of Georg Simmel's social geometry. Cybergeo. European Journal of Geography [En ligne]. Epistémologie, Histoire de la Géographie, Didactique, document 30, consulté le 13 mars 2021 (1997). URL: http://journals.openedition.org/cybergeo/227; doi: https://doi.org/10.4000/cybergeo.227

Fabian, J.: Time and the Other. How anthropology makes its object. Columbia University Press, New York (1983)

Faris, R.E.L.: Chicago sociology: 1920-1932. Chandler, San Francisco (1967)

Fedor, C.G.: Social distances in a multi ethnic region. Social Research Reports. 13(1), 49-57 (2021). doi:https://doi.org/10.33788/srr13.1.5

Feuerbach, F.: Das Geheimnis des Opfers, ober der Mensch ist was er ißt. Lipzig: (1862)

Fricker, M.: Epistemic injustice. Power and the ethics of knowing. Oxford University Press, Oxford (2009)

Fujii, T., Hanya, M., Kishi, M., Kondo, Y., Cates, M.E., Kamei, H.: An internet-based survey in Japan concerning social distance and stigmatization toward the mentally ill among doctors, nurses, pharmacists, and the general public. Asian Journal of Psychiatry. 36, 1-7 (2018). doi:https://doi.org/10.1016/j. ajp.2018.05.017

Geertz, C.: The interpretation of cultures. Basic Books, New York (1973)

Gentry, C.S.: Social distance regarding male and female homosexuals. J. Soc. Psychol. 127, 199-200 (1987). doi:https://doi.org/10.1080/00224545.1987.9713680

Górska, P., Bilewicz, M., Winiewski, M., Waszkiewicz, A.: On old-fashioned versus modern homonegativity distinction: Evidence from Poland. J. Homosex. 64(2), 256-272 (2017). doi:https://doi.org/10.1080/00 918369.2016.1179029

Haney, C.A., Fein, S.B.: Correlates of social distance and gradients of deviance. Research Reports in Social Science 11(2), 25-42 (1968)

Harvey, L.: Myths of the Chicago School of sociology. Gower, Brookfield, VT: (1987) 
Hinrichs, D.W., Rosenberg, P.J.: Attitudes toward gay, lesbian, and bisexual persons among heterosexual liberal arts college students. J. Homosex. 43(1), 61-84 (2002). doi:https://doi.org/10.1300/J082v43n01_04

Hunt, C.L.: Social distance in the Philippines. Sociology and Social Research. 40, 253-260 (1956)

Istat: L'Italia in 150 anni. Sommario di statistiche storiche 1861-2010 (2011a). https://www.istat.it/it/ files//2019/03/cap_3.pdf

Istat: I redditi delle famiglie con stranieri (2011b). https://www.istat.it/it/files//2011/12/redditfamiglieconstranieri.pdf

Istat: Indagine sul reddito e le condizioni di vita (Eu-silc) (2019). https://www.istat.it/it/archivio/5663

Istat: Immigrati e nuovi cittadini (2021). https://www4.istat.it/it/immigrati

Istat: Serie storiche. https://www4.istat.it/it/prodotti/banche-dati/serie-storiche

Jahoda, M., Lazarsfeld, P.F., Zeisel, H.: Die Arbeitslosen von Marienthal. Verlag S. Hirzel, Leipzig (1933)

Kinloch, G.C.: Race, socio-economic status, and social distance in Hawaii. Sociology and Social Research 57(2), 156-167 (1973)

Koc, Y., Anderson, J.R.: Social distance towards Syrian refugees: The role of intergroup anxiety in facilitating positive relations. J. Soc. Issues. 74(4), 790-811 (2018). doi:https://doi.org/10.1111/josi.12299

Koselleck, R.: Vergangene Zukunft. Zur Semantik geschichtlicher Zeiten. Suhrkamp, Frankfurt am Main (1979)

Kovačević, J., Radovanovic, V.: Social distance towards students with disabilities in inclusive education. International Journal of Disability, Development and Education. (2020). doi:https://doi.org/10.1080/1 034912X.2020.1856349

Koyré, A.: Du monde de l'«à-peu-près» à l'univers de la précision. Colin, Paris (1961)

Laumann, E.O., Guttman, L.: The relative associational contiguity of occupations in an urban setting. American Sociological Review. 31(2), 169-178 (1966). doi:https://doi.org/10.2307/2090902

Laumann, E.O., Senter, R.: Subjective social distance, occupational stratification, and forms of status and class consciousness: A cross-national replication and extension. American Journal of Sociology. 81(6), 1304-1338 (1976). doi:https://doi.org/10.1086/226225

Lazarsfeld, P.F.: The American soldier. An expository review. The Public Opinion Quarterly. 13(3), 377-404 (1949). doi:https://doi.org/10.1086/266089

Lee, M.Y., Sapp, S.G., Ray, M.C.: The reverse social distance scale. The Journal of Social Psychology. 136(1), 17-24 (1996). doi:https://doi.org/10.1080/00224545.1996.9923025

Leong, F.T.L., Tang, M.: Career barriers for Chinese immigrants in the United States. The Career Development Quarterly. 64, 259-271 (2016). doi:https://doi.org/10.1002/cdq.12059

Likert, R.: A technique for the measurement of attitudes. Archives of Psychology. 140, 1-55 (1932)

Mather, D.M., Jones, S.W., Moats, S.: Improving upon Bogardus: Creating a more sensitive and dynamic social distance scale. Survey Practice. 10(4), 1-9 (2017). doi:https://doi.org/10.29115/SP-2017-0026

Maurer, T.W., Keim, C.: Teaching about prejudice with a Bogardus social distance scale activity: Replication and extension. International Journal for the Scholarship of Teaching and Learning. 12(1), 1-10 (2018). doi:https://doi.org/10.20429/ijsotl.2018.120107

McAllister, I., Moore, R.: Social distance among Australian ethnic groups. Sociology and Social Research 75(2), 95-100 (1991)

McKee, J.B.: Sociology and the race problem. The failure of a perspective. University of Illinois Press, Urbana (1993)

Merton, R.K.: Social theory and social structure. Free Press, Glencoe (1949)

Morgan, H.: Social distance: Self reports by black and white school age children. The Negro Educational Review. 57(1-2), 15-33 (2006)

Morsbach, H., Morsbach, G.: Attitudes of South Africans towards various national and racial groups. International Journal of Psychology. 2(4), 289-297 (1967). doi:https://doi.org/10.1080/00207596708247225

Nataraj, P.: Social distance within and between castes and religious groups of college girls. J. Soc. Psychol. 65(1), 135-140 (1965). doi:https://doi.org/10.1080/00224545.1965.9919590

Nix, J.V., BlairLoy, M.: Cyberstratification and social distance over the internet: using the Bogardus scale to measure prejudice among WWW users. mimeo. (2000)

Owen, C., Eisner, H., McFaul, T.: A half-century of social distance research: National replications of Bogardus' studies. Sociology and Social Research 66, 80-98 (1977)

Park, R.E.: The concept of social distance. Journal of Applied Sociology 8, 339-344 (1923)

Parrillo, V.N., Donoghue, C.: Updating the Bogardus social distance studies: A new national survey. The Social Science Journal. 42(2), 257-271 (2005). doi:https://doi.org/10.1016/j.soscij.2005.03.011

Prandy, K.: The revised Cambridge scale of occupations. Sociology. 24(4), 629-655 (1990). doi:https://doi. org/10.1177/0038038590024004005

Prandy, K., Jones, F.L.: An international comparative analysis of marriage patterns and social stratification. International Journal of Sociology and Social Policy. 21(4/5/6), 165-183 (2001). doi:https://doi. org/10.1108/01443330110789484 
Randall, N.H., Delbridge, S.: Perceptions of social distance in an ethnically fluid community. Sociological Spectrum. 25(1), 103-122 (2005). doi:https://doi.org/10.1080/027321790505360

Riesman, D.: Abundance for what? Doubleday, New York: (1964)

Roesch, C.: The social distance scale, Emory, S.: Bogardus and Californian interwar migration research offside the Chicago School. Journal of Migration History. 1(2), 200-214, (2015). doi: https://doi. org/10.1163/23519924-00102003

Rostova, A.V., Urgalkin, Y.A.: Empirical indicators of innovative readiness of the population: Experience of the application of the Bogardus scale. In: Ashmarina, S., Vochozka, M. (eds.) Sustainable growth and development of economic systems. contributions to economics, 135-142. Springer, Cham (2019). doi:https://doi.org/10.1007/978-3-030-11754-2_10

Sacks, M.A., Lindholm, M.: A room without a view: Social distance and the structuring of privileged identity. In: Levine-Rasky, C. (ed.) Working through whiteness. International perspectives, 129-151. State University of New York Press, NY (2002)

Sakuragi, T.: The relationship between attitudes toward language study and cross-cultural attitudes. International Journal of Intercultural Relations. 30(1), 19-31 (2006). doi:https://doi.org/10.1016/j. ijintrel.2005.05.017

Sell, R.R.: Relative social distance: An example from Cairo. Sociology and Social Research 74(2), 80-84 (1990)

Simmel, G.: Die Grosstadt, Vorträge und Aufsätze zur Städteanstellung. Zahn und Jaensch, Dresden (1903)

Simmel, G.: Soziologie. Untersuchungen über die Formen der Vergesellschaftung. Duncker \& Humblot, Leipzig (1908)

Singh, K.K.: Social distance among four occupational groups. Indian Journal of Applied Psychology 2(1), 21-27 (1965)

Smith, M.W.: Measuring ethnocentrism in Hilo, Hawaii: A social distance scale. Sociology and Social Research 54(2), 220-236 (1970)

Sorokin, P.A., Merton, R.K.: Social time: A methodological and functional analysis. The American Journal of Sociology. 42(5), 615-629 (1937). doi:https://doi.org/10.1086/217540

Spinney, R.G.: City of big shoulders. A history of Chicago. Northern Illinois University Press, Dekalb (2000)

Staats, G.R.: Stereotype content and social distance: Changing views of homosexuality. J. Homosex. 4(1), 15-27 (1978). doi:https://doi.org/10.1300/J082v04n01_02

Thurstone, L.L., Chave, E.J.: The measurement of attitude. Ā psychophysical method and some experiments with a scale for measuring attitude toward the church. University of Chicago Press, Chicago (1929)

Thyne, M., Woosnam, K.M., Watkins, L., Ribeiro, M.A.: Social distance between residents and tourists explained by residents' attitudes concerning tourism. Journal of Travel Research. 61(1), 150-169 (2022). doi:https://doi.org/10.1177/0047287520971052

Tusini, S.: Simpatrici e allocronici. Una riflessione sul profilo spazio-temporale dei migranti per rileggere il concetto di mondo sociale di Schütz. Sociologia e Ricerca Sociale. 105, 51-85 (2014). doi:https://doi. org/10.3280/SR2014-105002

Tusini, S.: Migrazioni e identità: una prospettiva diacronica per gli indicatori di integrazione. Sicurezza e scienze sociali. 8(1), 106-120 (2020). doi:https://doi.org/10.3280/SISS2020-001010

Walzer, M.: Spheres of justice. A defence of pluralism and equality. Basic Books, New York (1983)

Wark, C., Galliher, J.F.: Emory Bogardus and the origins of the social distance scale. American Sociologists. 38, 383-395 (2007). doi:https://doi.org/10.1007/s12108-007-9023-9

Weaver, C.N.: Social distance as a measure of prejudice among ethnic groups in the United States. Journal of Applied Social Psychology. 38, 779-795 (2008). doi: https://doi.org/10.1111/j.1559-1816.2007.00326.x

Woosnam, K.M., Lee, Y.J.: Applying social distance to voluntourism research. Annals of Tourism Research. 38(1), 309-313 (2011). doi:https://doi.org/10.1016/J.ANNALS.2010.06.003

Yang, A.: Building a cognitive-sociological model of stereotypes: Stereotypical frames, social distance and framing effects. Howard Journal of Communications. 26(3), 254-274 (2015). doi:https://doi.org/10.10 80/10646175.2015.1049757

Yunkyung, K., Bilge, M.: How social distance shapes human-robot interaction. Int. J. Hum Comput Stud. 72(12), 783-795 (2014). doi:https://doi.org/10.1016/j.ijhcs.2014.05.005

Zaidi, S.M.: Students' attitude toward living with different ethnic groups. Journal of Social Psychology. 72, 99-106 (1967). doi:https://doi.org/10.1080/00224545.1967.9922303

Zerubavel, E.: Hidden rhythms. Schedules and calendars in social life. University of Chicago Press, Chicago (1981)

Zerubavel, E.: The standardization of time. A sociohistorical perspective. American Journal of Sociology. LXXXVIII. 1, 1-23 (1982). doi:https://doi.org/10.1086/227631

Publisher's Note Springer Nature remains neutral with regard to jurisdictional claims in published maps and institutional affiliations. 